\title{
Ações e possibilidades de prevenção de acidentes com crianças em creches de Fortaleza, Ceará
}

\author{
Actions and possibilities of accidents prevention \\ with children in daycare at Fortaleza, Ceará State
}

Luiza Jane Eyre de Souza Vieira ${ }^{1}$

Rochelle Cíntia M ilitão M aciel Carneiro ${ }^{2}$

MirnaAlbuquerque Frota ${ }^{1}$

Ana Lúcia Araújo Gomes ${ }^{3}$

Lorena Barbosa Ximenes ${ }^{4}$

${ }^{1}$ Centro de Ciências da Saúde, M estrado em Saúde

Coletiva. Universidade de Fortaleza. Av. Washington

Soares 1321, Edson

Queiroz. 60811-905

Fortaleza Ceará.

janeeyre@unifor.br

${ }^{2}$ Centro deCiências da

Saúde, Departamento de

Enfermagem, Universidade

deFortaleza.

${ }^{3}$ Estratégia Saúde da

Família, Prefeitura

M unicipal deFortaleza.

4 Programa de

Pós-Graduação em

Enfermagem, Faculdade de

Farmácia, Odontologiae

Enfermagem, Universidade

Federal do Ceará.
Abstract This paper describes the daily of infantile education teachers in day-cares in the city of Fortaleza, Ceará, Brazil as well asthe developed actions and the possibilities of prevention accidents' with children, in this educative space of health care. It is a descriptivestudy, using a qualitative approach that involved 17 day care teachers working at the $6^{\text {th }} \mathrm{Re}$ gional Executive Office (Fortaleza, Ceará, Brazil) in the year of 2004. A semi-structured interview was used to collect the data, which was analysed using the Collective Subject Discourse (CSD) technique. The results showed that teachers believe that this type of accident is preventable through family orientation, physical modifications of house spaces and creation and enforcement of specific laws. They recognise children's agility and curiosity, which facilitate the occurrence of accidents. In their practic$\mathrm{es}$, they report and suggest vigilance, physical changes at the day care centers, and education, through orientation directed to children, teachers, parents (or care givers), and the community. Therefore, health care professionals should share their 'caring' practice with professionals in the educational area, not only in order to prevent accidents and other human health afflictions, but also to expand concepts that contribute Health Promotion.

Key words Accidents, Children, Children daycare, Prevention
Resumo Esteestudo descreve o cotidiano deprofessoras da educação infantil, em creches de Fortaleza, Ceará, Brasil, bem como as ações desenvolvi das eas possibilidades de prevenção de acidentes com crianças, nesse espaço educativo e de cuidado à saúde. Trata-se de um estudo descritivo, com abordagem qualitativa, realizado com 17 professoras de Educação Infantil, que trabal havam em creches da Secretaria Executiva Regional VI, em Fortaleza, Ceará, em 2004. A entrevista semi-estruturada conduziu à coleta de dados e esses foram analisados à luz do Discurso do Sujeito Coletivo (DSC). Os resultados evidenciaram que as professoras concebem esse tipo de acidente como passível de prevenção mediante a orientação à família, alteraçõesfísicas no espaço domiciliar e elaboração e cumprimento de leis específicas. Reconhecem que a agilidade e curiosidade da criança favorecem a ocorrência dos acidentes. Em suas práticas, relatam e propõem vigilância, mudanças na estrutura física das creches e educação por meio de orientações às crianças, professores, pais ou responsáveis, estendendo-se à comunidade. Portanto, é preciso que os profissionais de saúde compartilhem sua prática de cuidado com os profissionais do setor da educação, não só prevenindo acidentes e outros agravos à saúde humana, mas, sobretudo, ampliando conceitos que contribuam com a Promoção da Saúde.

Palavras-chave Acidentes, Crianças, Creches, Pre venção 


\section{Introdução}

A partir da inter-relação das políticas de educação e saúde, torna-se imperativo discorrer sobre como se operacionaliza essa articulação, pois, consoante preconizam as diretrizes da Política Nacional de Redução da M orbimortalidade por Acidentes eViolência, o professor deeducação infantil épeça fundamental na promoção da saúde. Este deve buscar a adoção de hábitos e estilos de vida saudáveis e contribuir com a criação de ambientes seguros e favoráveis à saúde.

Essa importância é justificada porque o professor da educação infantil constitui um elo entrea criança e a família - alertando e orientando, durante toda a infância, quanto aos riscos eà prevenção dos acidentes domésticos mais comuns.

Apesar das diretrizes da política argumentar queo acidenteéum evento não intencional eevitável, causador de lesões físicas ou emocionais, continua adotando a terminologia "acidente"; contudo, retira a conotação de fortuito e casual, assumindo a noção de quetais eventos são previsíveise preveníveis. Acrescenta que esses acidentes "são passíveis de prevenção por intermédio de orientação familiar, alterações físicas do espaço domiciliar, elaboração e cumprimento de leis específicas" ${ }^{1}$.

N esse sentido, no âmbito da educação infantil, outros direitos foram gradativamente adquiridos a partir da década deoitenta. A Constituição Federal de 1988 oficializa a garantia da educação infantil em creches e préescolas, propondo ser isso um dever do Estado e um direito da criança (artigo 208, inciso IV). Em 1990, entrou em vigor o Estatuto da Criança e do Adolescente (ECA), quetambém destaca o direito da criança a esse atendimento. Em 1996, a Lei de Diretrizes e Bases da Educação $\mathrm{N}$ acional (LDB) estabeleceu o vínculo do atendimento às crianças de zero a seis anos com a educação, decretando ser um dever deo Estado garantir atenção gratuita em creches, para crianças de zero a três anos, e em pré-escolas, para escolares de quatro a seis anos ${ }^{2}$.

Em 1998, o Ministério da Educação e do Desporto propôs o Referencial Curricular Nacional para a Educação Infantil (RCNEI), que constitui um conjunto de referências e orientações pedagógicas que visam contribuir com a implantação ou implementação de práticas educativas de qualidade que possam promover e ampliar as condições necessárias para o exercício da cidadania das crianças brasileiras ${ }^{3}$.

Sob essa nova ótica, o $\mathrm{RCNEI}^{3}$ determina que as creches devam dispor de um serviço, não somente de cuidados básicos essenciais, mas, sobre- tudo, da complementaridade entre os conceitos de saúde e de educação como pilares para atenção à criança, que tem esse ambiente como segundo lar.

Para que haja, no entanto, uma educação de qualidade, voltada ao processo de educação em saúde, também é necessária a formação dos profissionais, assegurando e instrumentalizando uma efetiva colaboração como agentes centrais do ensino, aprendizagem e cuidado à saúde. Para Rossetti ${ }^{4}$, "é preciso formar o profissional cuidador, por meio de observações, discussões e reflexões sobre suas ações cotidianas no interior da creche ou da pré escola".

Além disso, os profissionais de educação infantil - professores e auxiliares - que trabalham em creches têm a tarefa de cuidar de crianças e, para isso, precisam estar cônscios para reconhecer sinais de risco e perigo para elas. Uma das formas para minimizar esses riscos é promover a educação em saúde para mobilizar pessoas da família e profissionais na prevenção de acidentes infantis $5^{5-10}$.

Além do investimento em políticas públicasque respondam ao desafio da redução dos acidentes, é necessário, também, que os professores e os auxiliares sejam proativos e capazes de reconhecer esses riscos, propondo soluções em tempo hábil para evitar acidentes, sequelas e óbitos. Trata-se, pois, de uma educação básica em cadeia.

Nessa equipe, esses profissionais devem identificar as fases de desenvolvimento da criança que favorecem a assimilação de novos conteúdos e vivências, para que elas sejam agentes multiplicadores de conhecimento e atitudes preventivos para a família e a comunidade.

Outro aspecto a considerar no cotidiano da prática pedagógica é o desenvolvimento de ações voltadas à prevenção de acidentes em crianças. Essas ações devem se concretizar a partir do conhecimento e das capacidades prévias adquiridas, somados à busca contínua por conhecer e apreender, aprender e ensinar, descobrindo junto com as famílias e comunidade quais são os melhores caminhos para a redução de danos à saúde das crianças. A concepção de Freire ${ }^{11}$ ressalta que "quem ensina aprende ao ensinar equem aprende ensina ao aprender".

Diante do que preconizam as políticas direcionadas à saúde e à educação infantil, o estudo delineia como objetivo descrever o cotidiano de professoras da educação infantil que trabalham em creches, em Fortaleza, Ceará, Brasil, bem como as ações desenvolvidas e as possibilidades de prevenção deacidentes com crianças, nesse espaço educativo e de cuidado à saúde. 


\section{Percurso metodológico}

Situando o leitor na trajetória investigativa desta pesquisa, por volta de 1995, a Prefeitura Municipal de Fortaleza (PM F) adotou uma subdivisão técnica da cidade, objetivan do facilitar a gestão eo acesso da população aos serviços prestados por essa instituição. Desse processo, surgiram seis secretarias executivas regionais (SER), dispostas estrategicamente, agrupando, para cada uma delas, os bairros adjacentes aos locais onde fisicamente se estabeleceram.

Esteestudo foi desenvolvido na SER VI, queéa secretaria regional com o maior número de bairros e, como as demais, reflete um perfil de socioeconomia dicotômico - com áreas nobres e economicamente privilegiadas e setores desprovidos dos recursos mínimos necessários à sobrevivência humana: água potável para o consumo, moradia adequada, saneamento básico, educação de qualidade, além de outras privações socioeconômicas e sanitárias.

A área adstrita da SER VI atualmente engloba 27 bairros: Alto da Balança, Aerolândia, Jardim das Oliveiras, Dias Macêdo, Parque M anibura, Cidade dos Funcionários, Cajazeiras, Castelão, M ata-Galinha, Passaré, Parque Dois I rmãos, Barroso, Parque Iracema, Cambeba, M essejana, Jangurussu, Ancuri, Pedras, Paupina, Coaçu, Guaperu, Curió, Lagoa Redonda, Alagadiço Novo, Sabiaguaba, Lagoa da Sapiranga e Edson Queiroz ${ }^{12}$.

Vale ressaltar que essa área tem setores importantes e representativos para toda a cidade, tais como duas universidades, três faculdades, um fórum, um centro de reciclagem de lixo, o maior estádio de futebol do Nordeste, a sede do Banco do Nordeste, do centro administrativo do Governo do Estado, dentre outros setores importantes para a área socioeconômica e cultural.

Essa SER VI conta com 24 creches: onze pertencentes à ação continuada, doze municipais/comunitárias e uma ligada à O peração Fortaleza (OPEFOR). A PM F disponibiliza recursos materiais e humanos para as creches que atendem crianças, socialmente desfavorecidas, com idade de um a três anos e meio.

Quanto aos incentivos dispensados pela PM, existem diferenças: (1) as doze creches municipais/ comunitárias recebem apoio financei ro, alimentar e de recursos humanos - três ou quatro professores e auxiliares de sala de aula - da SER VI, sendo esses profissionais vinculados à Prefeitura de Fortaleza, de onderecebem vencimentos etreinamento regular e funcionam sem interrupção no atendimento à clientela, durante 0 ano letivo; (2) as onze creches pertencentes à ação continuada recebem apoio da SER VI da PMF somente quanto à alimentação das crianças, sendo que os profissionais são contratados, treinados e remunerados pela própria comunidade onde a creche está instalada; (3) a creche vinculada à O PEFO R, administrativamente, se insere no quadro de creches da SER VI da PMF, por estar na área adstrita; porém, tanto os recursos materiais quanto os humanos são provenientes da OPEFOR, e as atividades pedagógicas são mantidas durante todo 0 ano letivo. Vale esclarecer que essas diferenças administrativas e financeiras não interferem no nível técnico nem no cuidado e atenção que essas professoras dispensam às crianças das creches.

Partindo do interesse de descrever as ações educativas desenvolvidas por professoras de educação infantil, quetrabal ham em creches, na prevenção de acidentes em crianças, optamos por um estudo descritivo com abordagem qualitativa, que, conforme ensina M inayo ${ }^{13}$, é capaz de [...] incorporar a questão do significado e da intencionalidade como inerentes aos atos, às relações, e às estruturas sociais, sendo essas últimas tomadas, tanto no seu advento quanto na sua transformação, como construções humanas significativas.

Assim, as participantes do estudo foram professoras das crianças usuárias de creches da SER $\mathrm{VI}$, tanto comunitárias como de educação continuada, quanto da OPEFOR. Os critérios de inclusão foram: ter sido contratado como profissional permanente pela Prefeitura de Fortaleza, no mínimo para o ano de 2004, como professor de creche daSER VI, independentemente desexo, idade, raça, classe social, religião, bem como aceitar participar de forma espontânea do estudo. Também adotamos como critério inclusivo o fato detodas as creches pesquisadas no período da coleta deveriam estar no decurso regular do ano letivo.

Para o contato com as creches, houve a mediação da coordenadora da Educação Básica da Regional VI, que disponibilizou a relação de endereços, telefones e coordenadores de todas as creches da SER VI, conferindo, assim, agilidade ao agendamento das visitas. Das 24 creches que compunham o universo, mantivemos contato com todas elas, mas apenas dezessete foram pesquisadas. Tal fato ocorreu porque duas creches estavam oficial mente fechadas, quatro temporariamentedesativadas ( $p e$ ríodo da pesquisa) pelo atraso no repasse de recursosfinanceiroseuma não aceitou participar do estudo. N esta, a coordenadora al egou indisponibilidade de tempo das professoras. Em cada creche pesquisada, foi eleita, de forma aleatória, uma professora, respeitando os critérios de inclusão citados. 
Os dados foram coletados nos meses de agosto e setembro de 2004, mediante a utilização de entrevistas semi-estruturadas - respeitando local e horário previamente definidos pelos sujeitos do estudo - as quais foram gravadas e transcritas na íntegra. 0 ambiente das entrevistas foi privativo; porém, em razão da dinâmica das atividades das creches e do horário em queforam realizadas al gumas das entrevistas, nem sempre esse ambiente foi calmo e silencioso, mas isso felizmente não interferiu nas falas dos entrevistados nem nas suas respectivas transcrições. A princípio, o gravador assustou al gumas das respondentes que temiam ser identificadas e prejudicadas com seus depoimentos; no entanto, após exaustivas explicações sobre o objetivo e metodologia da pesquisa, elas se tranquilizaram, assinaram o termo de consentimento livre e esclarecido, não havendo, portanto, prejuízo ou inibição durante a aplicação do instrumento.

A análise dos dados ocorreu à luz do discurso do sujeito coletivo (DSC) que, segundo Lefévre e Lefévre $^{14},[\ldots]$ trata-se de um eu sintático que, ao mesmo tempo em que sinaliza a presença de um sujeito individual do discurso, expressa uma referência coletiva na medida em queesse eu fala pela ou em nome de uma coletividade. Esse discurso coletivo expressa um sujeito coletivo, que viabiliza um sujeito social.

O estudo foi avaliado pelo Comitê de Ética em Pesquisa (COÉTICA), da Universidade de Fortaleza, epela Coordenação do Setor de Educação Básica da Regional VI, da Prefeitura M unicipal de Fortaleza, e foi aprovado nessas duas instâncias.

\section{Resultados}

Descrição das professoras do estudo

As dezessete participantes apresentavam idade compreendida entre 22 e 38 anos, a maioria (11) com escolaridade superior completa/incompleta e as demais (6) afirmaram ter concluído o nível médio. Todas disseram que participaram de algum curso de profissionalização ou aperfeiçoamento voltado à educação infantil; onze relataram que trabal havam em creches há mais de três anos; cinco informaram ter experiência entreum etrês anos nessa prática e uma afirmou que trabalhava há um ano com educação infantil. Em relação à faixa etária das crianças, catorze disseram que trabalhavam com crianças de dois a três anos e três referiram quelidavam com a faixa etária compreendida entre um e dois anos.

\section{Conhecimento sobre acidente doméstico}

Para as professoras de educação infantil, o conhecimento sobre acidentes domésticos é de suma importância, na tomada de decisão, para prevenilos e assim promover a saúde da criança. Com a análise da temática, emergiram cinco idéias centrais (IC).

Dessas, a primeira foi identificada como "Falta devigilância, descuido dos pais ou responsáveis, principalmente das mães". Nesse sentido, as participantes do estudo tendem a responsabilizar principalmente a mãe pelo cuidado integral de todos os fiIhos: a mãe tem muita culpa, acontece mesmo por falta de vigilância, de cuidado da mãe ou do responsável pela criança. Tem mãe que não tá nem aí pra criança.

Os trabalhos de Souza ${ }^{5,6}$ e Pacheco e Dupret ${ }^{15}$ reafirmam quea mulher, na cultura ocidental, sempre assumiu esse papel de principal cuidadora e educadora dos filhos. A partir do momento em que saiu - por opção ou imposição social ou financeira - do espaço privado do lar para assumir também o espaço público, acumulou papéis, sendo ainda responsabilizada pel os eventuaisinfortúniosque viessem a acontecer com os seus próprios filhos ${ }^{10,16}$.

É interessante frisar que essas mesmas mulheres, mães e trabalhadoras, é que apontam a causa dos acidentes domésticos com crianças como sendo o descuido ou falta devigilância maternos. Como a grande maioria dessas mulheres precisa deixar 0 lar para contribuir, ou mesmo garantir o sustento da família, vale ressaltar que essas delegam os cuidados e a educação dos filhos menores aos outros que são maiores, às creches ou até mesmo a pessoas sem vínculo pessoal ou profissional com as crianças. Muitas vezes, esses responsáveis são desconhecedores do crescimento, desenvolvimento e das necessidades das crianças, fato que favorecea ocorrência de acidentes domésticos elas $5^{5,6,17}$.

A segunda IC, "Acidentes que mais acontecem com crianças", mostra a vivência e o conhecimento dos riscos e perigos que uma casa pode conter. Cozinha, banheiro, janelas, tomadas elétricas são al guns dos fatores citados que podem levar à ocorrência de acidentes domésticos. Quedas, queimaduras com vela, o fogão com água fervente, além de choques elétricos, também são referidos como injúriasfrequentes. As verbalizaçõesa seguir ilustram esse entendimento: 0 que eu entendo sobre acidente doméstico équeda, chão molhado, queimaduras, choque elétrico e acidente na cozinha. Também no banheiro, corte, beber veneno. 0 mais conhecido é com vela. A contece muito de deixar a criança subir nos móveis, virar panela de água fervendo. 
Esse dado revela que, na prática, essas profissionais vivenciam o que a literatura retrata sobre a ocorrência deacidentes com crianças, sendo os mais comuns na faixa etária de até três anos: quedas, queimaduras e intoxicações por produtos domiciliares $6,8,18$.

Em associação, a literatura também reforça essa IC, ao demonstrar que existem fatores comumente encontrados no lar que favorecem os acidentes domésticos: fatores químicos (substâncias destinadas à higiene pessoal, limpeza doméstica e drogas com fins terapêuticos), físicos (banheiros, cozinha, escadas, janelas, quintal e piscina, eletricidade e calor), biológicos (animais domésticos, animais peçonhentos, roedores e plantas venenosas), estruturais (formação da família e condições ambientais, sociais e econômicas), culturais ( hábitos, estilo de vida e crenças familiares), dentre outros ${ }^{19-21}$.

A consideração de que "acidentes com crianças são comuns porque criança é muito impulsiva, curiosa, éda idade, são danadas mesmo" caracteriza as fases de crescimento e desenvolvimento da criança. É comum esses acidentes com crianças porque tudo pra elas é novidade. É normal acidentar-se no sentido de que toda criança, cai, se corta, se queima, leva choque, porque elas são danadas mesmo. Além disso, criança não tem responsabilidade!

No primeiro ano de vida, a criança começa a se movimentar no berço, sentar, manter-se em pé e vivencia a fase oral. São frequentes as quedas, intoxicações por produtos domiciliares, aspiração de corpos estranhos e queimaduras. Do segundo ao quinto ano de vida, a criança já corre, pula, é mais curiosa e ativa, explicando as queimaduras, intoxicações, quedas e acidentes de trânsito, comuns nessa fase da vida $5,8,21,22$.

Conhecendo essa realidade, algumas participantes consideram que "acidentes domésticos são previsíveis e preveníveis", concordando assim com o que propõem Gikas et al. ${ }^{8}$, que dizem que "o acidentetem causa, origem e determinantes epidemiológicos como qualquer outra doença e, em consequência, pode ser evitado e controlado".

Os sujeitos do estudo descrevem situações específicas que podem e devem ser abordadas: ter atenção com material inflamável, cabos de panela voltados para dentro quando sobre o fogão, atentar para colocar plugs nas tomadas elétricas, tirar de perto das crianças objetos que podem causar acidentes, pois, caso contrário, existe grande probabilidade desses ocorrerem.

Algumas entrevistadas adotam uma atitude de aceitação ou conformismo em relação aos acidentes com crianças. Estas acreditam que a ocorrência é normal pelo fato deser a casa ou a creche o local onde as crianças passam a maior parte do tempo, aumentando, assim, as oportunidades de ocorre rem acidentes.

Nessa linha de raciocínio, estudiosos relatam que essa percepção é compreensiva, porém não aceitável, na medida em quea residência ea creche são ambientes que favorecem acidentes infantis, a exemplo da disposição dos móveis, exposição de objetos minúsculos e passíveis deserem engolidos, colocação de produtos emedicamentos no alcance das crianças, dentre outros riscos ${ }^{9,10,19,22-24}$.

Trabalhos sobre as injúrias não intencionais ${ }^{25-}$ ${ }^{27}$ trazem à tona a necessidade de se investigar as possibilidades que configuram risco para a criança e apontam os fatores ambientais, familiares, educacionais, culturais, econômicos, sociais, políticos, dentre outros, contribuindo na perpetuação dessas injúrias. Por outro lado, os pais desconhecem a evolução do desenvolvimento dosfilhos e parecem não ter consciência da capacidade criativa que favorecem os acidentes.

Orientar antecipadamente quanto às modificações previstas de crescimento e desenvolvimento contribui para alertá-los sobre os riscos de acidentes mais comuns em cada faixa etária e os meios de minimizar os agravantes que podem precipitar os acidentes. Essa responsabilidade é assumida pelas professoras da creche, para compensar a carência educacional familiar, mesmo diante dos riscos de estar com crianças cada vez maiságeise inteligentes.

\section{Abordagem sobre acidentes domésticos na creche}

Por unanimidade, os sujeitos da pesquisa garantiram discorrer sobre a prevenção de acidentes domésticos na creche. Essa abordagem preventiva é efetivada "através de cuidados imediatos e atenção direta com as crianças", porque não existem outros meios disponíveis na creche, a não ser o cuidado que a professora tem com a criança. Asseguram que estão sempre vigilantes, evitando levar à sala de aula produtos inflamáveis, deixar tomadas elé tricas sem proteção, estando atentos às subidas nos armários e cadeiras. Essas ações têm objetivos de evitar queimaduras, quedas, choques elétricos, dentreoutras injúrias não intencionais. As participantes acrescentaram que todos na creche têm o "poder de brigar" com as crianças, na tentativa de evitar a ocorrência de acidentes e demonstrar que todos são responsáveis por todas elas.

No momento, nossa prevenção é só o cuidado direto. A gente procura no lugar que a gente trabaIha, onde tem criancinhas, não ter fósforo, a gente não usa na sala alguma coisa que pode causar aci- 
dente. A prevenção quea gente trabalha éo cuidado, porque a gente não tem tantos meios, a não ser 0 cuidado que o professor tem com o aluno. Sem dúvida alguma, a vigilância ativa das crianças é uma forte aliada na prevenção de acidentes domésticos, visto que, de acordo com as diversas etapas de crescimento e desenvolvimento, é natural que a criança demonstre curiosidade crescente nas suas descobertas.

Outras professoras buscam operacionalizar a prevenção deacidentes na creche, "orientando eeducando as crianças", e acreditam que, por meio das conversas do cotidiano, realizadas nas "rodinhas de conversa", é possível ir orientando as crianças para que elas não se machuquem com os brinquedos, não caiam nem se cortem. Essas participantes acrescentam que, apesar de serem "pequenininhos", é possível começar a orientá-los no dia a dia e, aos poucos, ir formando potenciais multiplicadores de cuidado, porque essas crianças, uma vez orientadas, levam as informações à família, favorecendo o estabelecimento de atitudes preventivas.

Com as crianças a gente sempre conversa: quando estão brincando, pra não se machucarem com 0 brinquedo. Quando estão correndo, ter cuidado pra não cair, não se machucar. A gente faz esse trabalho pra eles levarem até em casa, porque através daqui, atingimos as famílias, e por mais que sejam crianças de trêsanos, eles prestam atenção, chegam em casa e dizem: "a tia disse que não pode pegar isso". Essa conversa com as crianças é sempre feita na rodinha de conversa.

Pacheco e Dupret ${ }^{15}$, ao investigarem os serviços oferecidos por creches do Programa Rio - Creches, da Prefeitura do Rio de Janeiro, esclareceram que a creche representa um espaço privilegiado para oferecer à criança oportunidades e alternativas que estimulem as suas potencialidades, pois a criança estará em interação constante com outros sujeitos que interferirão em seu desenvolvimento.

Esse processo deorientação eeducação das crianças, porém, não pode ser realizado de qualquer forma. É preciso lembrar que o mundo da criança é caracterizado pelas fantasias e descobertas. Falar a linguagem dos adultos e "brigar" com os peque ninos pode levar à reversão de valores e isso impede, no final, o alcance dos objetivos desejados.

Outras professoras já abordam a prevenção deacidentes domésticos" orientando as crianças pelo lúdico" e desenvolvem atividades com a utilização de peças teatrais, fantoche, desenho epintura. D esse modo, elas trazem a informação à criança para que ela a compreenda ea absorva mais tranquilamente. Reconheceram "que se perde muito apenas orientando com palavras", por isso, elas adotam o lúdico no dia a dia da criança, vivenciando junto delas o que Ihes parece compreensível.

A gente faz teatro, fantoches pra eles explicando. Usa pintura, desenho pra mostrar. Porque a faixa etária é essa (até três anos e meio) e é assim que eles entendem. Conseguimos, assim, maisatenção das crianças do que um adulto ficar falando, explicando $\mathrm{A}$ gente procura trazer essa prevenção para o dia a dia.

Vieira et al. ${ }^{28}$, ao descreverem a utilização de atividades lúdicas como estratégias preventivas de acidentes em crianças no contexto escolar, salientaram que associar ações preventivas, simulações de casos adotando o lúdico como referencial éuma possibilidade a ser percorrida na tentativa de minimizar os acidentes domésticos.

\section{Prevenção de acidentes com crianças}

A orientação sobreprevenção de acidentescom crianças, para os professores de educação infantil, deveser incluída no currículo mínimo desses profissionais, visto que é durante as atividades do cotidiano que ocorre o maior número de acidentes com crianças.

O Referencial Curricular Nacional para a Educação Infantil (RCNEI) de 1998 preconiza que os profissionais de educação infantil sejam polivalentes, ou seja, capazes detrabalhar com diversos conteúdos teóricos e práticos, desde os cuidados básicos até os conhecimentos específicos ${ }^{3}$.

A prevenção de acidentes em crianças, no entanto, ainda é uma incógnita para a maioria dos sujeitos desse estudo, porquanto muitos deles não conseguem compreender o significado da palavra preven ção e, comumente, associam-na com primeiros socorros.

As professoras reconhecem a importância da prevenção de acidentes com crianças e algumas admitem que, nem a prefeitura, nem elas mesmas, nunca discutiram sobre o tema. Na verdade, essas professoras detêm apenas alguns conhecimentos sobre primeiros socorros, aliás já "apagados na memória". A prefeitura nunca deu curso pra gente sobre isso. Também nunca fiz curso sobre isso. A gente vem aprendendo com o dia a dia. Quando eu vim trabalhar aqui na creche, eu já sabia um pouco sobre acidentes com crianças porque eu fiz um curso na prefeitura há muito tempo, dez anos, eu acho! $M$ as, esse curso falava de primeiros socorros, de prevenção não!

Outras participantes confundem "prevenção de acidentes e primeiros socorros" e dizem que receberam orientações sobre como proceder com crianças nos casos de queda, cortes, queimaduras, choque elétrico, dentre outros agravos, mas, em ne- 
nhum momento, abordam a prevenção, revelando que também não receberam informação sobre 0 assunto, e que trabalham com as crianças apenas o pós-acidente.

Há muito tempo, há nove anos atrás, quando eu fiz o treinamento de uma semana sobre educação infantil, tinha como a gente proceder com crianças nos acidentes. Depois disso não tive mais nenhum curso. Eles abordaram como proceder numa queda: molhar a cabeça, dar água, um banho e dependendo do tombo, levar pra falar com a mãee contar pra ela. Era importante rever. Num curso que a gente fez de auxiliar de creche, teve um programa sobre acidentes. Preventivo. Explicaram os principais acidentes: queda, luxaç̧ões. Explicaram como éque deveria agir, o que não deveria ser feito. Quando acontece um acidente é que dá pra ver que eu não sei nada disso, faz tanto tempo que eu nem me lembro.

De certa forma, essa falta de discernimento é compreensiva, visto que, mesmo para aqueles que tiveram oportunidade de participar de cursos que abordaram a temática acidentes com criança, as orientações e o enfoque preventivo ficaram diluídos, pois o discurso das professoras converge para 0 atendimento de primeiros socorros. Essa prática reflete 0 antigo modelo biomédico da gestão da saúde, centrado na doença e contrapondo 0 atual modelo de vigilância à saúde.

As políticas públicas mundiais de saúde apostam em modelos de promoção da saúde, e isso requer dos profissionais da educação e da saúde 0 uso de práticas proativas nesse atendimento aos indivíduos, que devem ser "conscientizados" do papel que desempenham como sujeitos ativos desse processo.

Corroborando esse entendimento, é preciso unir esforços entre os serviços, famílias e comunidades para que sejam encontradas, coletivamente, soluções quefavoreçam melhores condições de vida aos povos, incentivando as avaliações diagnósticas e participativas que contribuam para as reorientações das práticas preventivas e promotoras de saúde ${ }^{29-33 .}$

Compreendemos também que a percepção da normalidade em torno da ocorrência de acidentes com crianças faz com que, inconscientemente, as professoras não consigam priorizar a prevenção, mas direcionem a atenção aos primeiros socorros.

Conhecimento das professoras para a prevenção de acidentes em creche

Ao indagarmos às professoras sobre seus conhecimentos para prevenirem acidentes, as respostas foram contraditórias: sim (IC1), em parte
(IC2) e não (IC3). Aquelas que afirmaram possuir conhecimento para prevenir acidentesjustificaram suas respostas fundamentadas na experiência profissional. Utilizam o senso comum em prol dessa causa, e consideraram, ainda, que têm muito para aprender, mas conseguem trabal har com o pouco de conhecimento adquirido, pois as respondentes disseram que cuidavam das crianças da creche como cuidariam dos seus próprios filhos.

Tô. Posso dizer que sim! Esse tempo todo aqui. Eu já presenciei muita coisa, muitos acidentes, não graves, claro! Já venho trabalhando com as crianças e os pais. Aqui dentro, a gente tenta evitar, faz 0 máximo, tem atenção. 0 pouco que a gente sabe, a genteusa, coloca em prática. Pelo conhecimento, acho que sempre temos que ter mais e mais. Acho que é pouco. Mas dá pra trabalhar. $N$ ão é fácil, mas tá dando certo.

Aquelas que admitiram trabalhar, de modo parcial, com a prevenção de acidentes, alegaram que não sabem como proceder com todos os tipos de ocorrências e que é preciso mais conhecimento sobre 0 assunto. Por esse motivo, elas perceberam a necessidade de constante aperfeiçoamento e solicitaram a presença de um profissional para orientá-las. M ais ou menos. Porque eu me lembro muito pouco do curso. Precisaria de um pouco mais de conhecimento. Em alguns pontos, sim! Era bom que tivesse sempre alguém reciclando, dizendo como é e como não é.

As professoras que enfatizaram o despreparo na prevenção de acidentes domésticos com crianças nem mesmo sabem se estão preparadas para atuar nessa área, demonstrando insegurança e inquietação. Não, eu acredito que não! Quer dizer, nem sei. Será que o que eu faço écerto? Precisaria ter um conhecimento maior pra afirmar com clareza que eu seria capaz.

Esses discursos demonstram quão frágil é o conhecimento que as profissionais de educação infantil pesquisadas possuem sobre acidentes domésticos com crianças, bem como reforçam a necessidade da urgente capacitação dessas pessoas, para atingir um grau plausível de atenção à criança usuária de creche, no que diz respeito à prevenção de acidentes domésticos.

Nesse sentido, Veríssimo e Fonseca ${ }^{33}$ enfatizam a idéia de que 0 atendimento à criança na creche demanda uma oferta de ações constituídas de atividades pedagógicas essenciais à criança. Para tanto, é preciso haver profissionais capacitados em conhecimentos ehabilidades específicos, tais como observar, interpretar e compreender os comportamentos e as necessidades infantis. 
Propostas de práticas educativas

na prevenção de acidentes

pelas professoras de creche

Com esteio no conhecimento empírico ena vivência das professoras de educação infantil, foram formados três discursos que retratam as necessidades e os desejos dessas profissionais no que diz respeito às práticas educativas sobre prevenção de acidentes.

Na primeira IC, foi salientada a "capacitação dos professores de educação infantil". Essas professoras sentem a necessidade de participar de encontros em que possam saber, objetivamente, como devem agir em relação à prevenção de acidentes domésticos com crianças usuárias de creches. Ampliando o raciocínio, também consideram que esse momento de encontro poderia, inclusive, ser um momento de "tira-dúvidas" deprofessores, pais e responsáveis, assim como um instante em que todos aprenderiam a "falar" a linguagem da criança, vivenciando trabalhos com o lúdico.

Em primeiro lugar, a gentedeveria ter uma palestra, de vez em quando, pra saber o que fazer. Queria mais orientação, quealguém me desse mais esclarecimento. Seria um momento para todos, professores e pais, tirarem suas dúvidas. Bom seria haver grupos de discussão com os professores, sempre com alguém lá da prefeitura, que saiba tirar nossas dúvidas, nos ensinar a trabalhar talvez com maisjogos, brincadeiras, teatro. Criança gosta dessas coisas. M as, pra isso, a gente tem que ser treinada. A SER VI não tem ninguém pra dar esses cursos não? É tão simples!

A segunda IC trata da "mudança na estrutura física das creches". É preciso que o ambiente das crianças seja preparado para recebê-las. M esas, cadeiras, banheiros, piso, paredes e móveis mere cem ser todos revistos para atender às necessidades da criança. Com certeza eu mudaria a estrutura: mesa, cadeira, seria tudo diferente.M udaria 0 piso, faria um banheiro mais eficiente.Eu não colocaria degraus aqui na creche, nem esses murinhos (que separam as salas de aula), tirava os cachorros, tiraria as portas, mudava os pisos dos banheiros. Construiria uma casa de brinquedos pra ensinar as crianças onde tá o perigo. Procuraria dentro da cre che quais os focos que podem gerar acidentes.

A concepção desse pensamento vai ao encontro do que preconiza o conceito de habitação saudável, queseaplica, desdea elaboração do projeto, microlocalização, construção, escolha earranjo dos materiais, à segurança dos elementos combinados, além da educação ambiental ${ }^{31}$ e essa, também, re laciona-se com a prevenção de acidentes que porventura aconteçam nesses espaços.
Quanto à estrutura física das creches municipais, todas são padronizadas. As salas de aula são separadas por semiparedes, em único espaço físico. Dentro de cada sala de aula, estão dispostas mesas e cadeiras de madeira, com acabamento em ferro, e brinquedos, de acordo com a faixa etária da turma. Os banheiros são revestidos de cerâmica lisa e os vasos sanitários são adaptados às crianças. $\mathrm{Na}$ entrada das creches, há degraus e, na lateral, existe areia num nível abaixo do "grande gal pão". N as creches de ação continuada e da O peração Fortaleza (OPEFOR), a estrutura física é variada, pois algumas das características ora descritas podem ser encontradas nessas creches e ainda outras, como janelas abertas, ganchos conhecidos como "pega-ladrão" em muretas próximas às salas deaula, tomadas baixas deenergia elétrica, brinquedos ou pedaços de brinquedos pequenos espaIhados por toda a creche, dentre outras.

Tudo isso pode ser descrito como focos que propiciam a ocorrência de acidentes com crianças. Falar em prevenir acidentes também passa pela revisão do ambiente em que essas crianças passam a maior parte do seu próprio tempo. Os trabalhos de Towner e Ward ${ }^{23}$ enfatizam que 0 ambiente doméstico tem grande potencial para o acidente eesse potencial se exacerba à medida que a criança permanece nele por longo período.

Outras respostas obtidas sobre essa questão priorizaram "a prevenção de acidentes com crianças, a partir de trabal hos em equipe, juntamentecom os pais e a comunidade", indo além dos muros da creche. Esse relato capta a participação de todos os responsáveis, inclusive da comunidade. As professoras que defendem essa idéia pensam em formar frentes de trabal ho para que todos sejam alertados e mobilizados em prol do benefício das crianças. Percebe-se que, nesse último discurso, há a compreensão de que todos precisam estar capacitados para a atenção à saúde das crianças.

$\mathrm{N}$ ão basta apenas adotar cuidados preventivos na creche ou no lar, visto ser necessário que esses cuidados também sejam efetivos em outros locais em quea criança frequenta. Eu juntaria um grupo e dividiria; uma parte vai fazer teatro, esse outro, uma pequena passeata com as crianças pra alertar a comunidade. Por aí. N ós iríamos trabalhar um projeto deprevenção deaci dentes, fazer reuniões com os pais, orientá-los da melhor maneira possível.

Em 2002, o Centro Nacional para Habitação Saudável ( $N$ ational Center for Healthy Housing) realizou oficinas que discutiram a relação entre a habitação ea saúde da criança. N esse sentido, Breysseet al. ${ }^{18}$ relatam que existenecessidade de se investigar sobre a ocorrência de acidentes domésticos e 
as consequências advindas desses agravos. Sugerem ainda que as questões sobre acidentes e medidas preventivas sejam incluídas nas pesquisas domiciliares para mel hor caracterizar aqueles acidentes não atendidos nos setores de emergência.

\section{Consideraçõesfinais}

O estudo descreveu o cotidiano de professoras da educação infantil que trabalhavam em creches e como desenvolviam suas atividades na prevenção de acidentes, representando a realidade vivenciada e por elas sentida em dezessete creches municipais da Secretaria Regional VI, da Prefeitura M unicipal de Fortaleza.

Observamos que essas professoras se aproximaram da idéia de prevenção de acidentes domésticos preconizada pela Política Nacional de Redução da M orbimortalidade por Acidentes e Violência, do M inistério da Saúde, que concebe esse tipo de ocorrência como passível de prevenção a partir da orientação da família, de alterações físicas no espaço domiciliar, além da elaboração e cumprimento deleis específicas.

Essas profissionais reconheceram, mesmo que empiricamente, as fases de crescimento e desenvolvimento da criança e souberam definir, exatamente, em que fases da vida ela émais "impulsiva" equer descobrir o "novo", favorecen do maisa ocorrência dos acidentes.

Por isso, em suas práticas, relataram e propuseram vigilância, mudanças na estrutura física das creches, educação por meio de orientações dadas às crianças, professores, pais ou responsáveis, estendendo-se até a comunidade einserindo atividades lúdicas.

Percebemos que há uma inadequação do emprego dos termos prevenção e primeiros socorros no discurso coletivo. Entendemos que isso possa acontecer em virtude de que os debates sobre as políticas públicas de saúde mundiais - que preconizam a Promoção da Saúde ao modelo biomédico curativo - nem sempre são efetivados em todas as instâncias. Acrescido a essa lacuna, detecta-se a falta de conhecimento de medidas simples e redutoras da ocorrência de acidentes domésticos com crianças.

Destacamos o fato de que essas profissionais, em seus depoimentos, pediram ajuda, literalmente, sobre orientação básica para melhor desenvolverem os trabal hos que fazem com as crianças nas creches. Demonstraram interesse sobre como proceder nos casos de acidentes, como atrair as famílias para a creche e como melhor educar as crianças, visando reduzir os índices de injúrias não intencionais. São conscientes deque, hoje, somentea vivência do dia a dia com os seus próprios filhos, inclusive, équelhes dá um pouco mais de conhecimento - nesse caso, trata-se do conhecimento empírico - bem como de segurança para trabaIharem melhor nas creches.

Portanto, é preciso que os profissionais de saúde compartilhem sua prática de cuidado com os profissionais do setor da educação e, com uma parceria coadunada em princípios e ações, efetivem as diretrizes que norteiam a escola promotora de saúde, não só prevenindo acidentes e outros agravos à saúde humana, mas, sobretudo, ampliando conceitos que contribuam com a promoção da saúde em comum acordo com a Política Nacional de Redução da M orbimortalidade por Acidentes e Violência, do M inistério da Saúde.

Alia-se a esse desafio o desenvolvimento de competências ehabilidadestécnicas ehumanas nos profissionais de educação infantil, que, formando parcerias com as famílias, fazem o indispensável elo entre as crianças e as creches.

\section{Colaboradores}

LJES Vieira propôs o tema, orientou todas as etapas do trabalho e realizou a revisão final do trabaIho. RCM M Carneiro fez o levantamento bibliográfico, coleta, análise preliminar dos dados e redação inicial. M A Frota, ALA Gomes eLB Ximenes contribuíram com a versão final do trabalho erevisão do texto final. 
Agradecimentos

Este artigo contou com auxílio material do Conse Iho Nacional deD esenvolvimento Científico eTecnológico, Processo n 50.4458/2004-3.

\section{Referências}

1. Brasil. M inistério da Saúde. Política Nacional de Redução da M orbimortalidade por A cidentes e Violência. Brasília: M inistério da Saúde; 2003.

2. Brasil. Ministério da Educação. Secretaria de Educação Básica. Política Nacional de Educação Infantil: pelo direito das crianças de zero a seis anos à Educação. Brasília: M EC/SEB; 2006.

3. Brasil. Ministério da Educação e do Desporto. Secretaria de Educação Fundamental. Referencial Curricular Nacional para a Educação Infantil. Brasília: Ministério da Educação e do Desporto;1998.

4. Rosseti C. A formação inicial e em serviço do professor/ educador para uma educação infantil de qualidade. I Congresso Norte-Nordeste e Psicologia. Salvador; 1999. Disponível em: http://www.ufba.br/ conpsi/ conpsi 1999/mesas.html

5. Souza LJEX, Barroso MGT. Envenenar é mais perigoso: uma abordagem etnográfica. Cogitare Enferm 1998; 3(1):13-20.

6. Souza LJEX, Rodrigues AKC, Barroso MGT. A família vivenciando o acidente doméstico: relato de uma experiência. Rev Latino-am enferm 2000; 8(1):83-89.

7. Pinheiro SA, M oreira MIBG, Freitas MA. Ensino mé dico e promoção à saúde em creche comunitária. Rev Assoc Med Brasil 2001; 47(4):320-324.

8. Gikas RMC, Schvartsman C, Fontana C. Promoção da segurança infantil. In: Issler H, Leone C, M arcondes $E$, organizadores. Pediatria na atenção primária. São Paulo: Sarvier; 2002. p.130-140.

9. Damasceno AKC, Barroso MGT. Diagnóstico epidemiológico de queimaduras em crianças. Revista Nursing 2004; 68(7):23-27.

10. Vieira LJES, Barroso MGT. Julgar e compreender: contradições da abordagem multiprofissional à família da criança envenenada. Acta Scientiarum Health Sciences 2004; 26(1):95-106.

11. Freire P. Pedagogia da autonomia: saberes necessários à prática educativa. 27ạ ed. São Paulo: Paz e Terra; 1996.

12. Prefeitura de Fortaleza. Informes sobre Educação. Prefeitura entregará 49 creches à população. 2004. Disponível em: http://www.fortaleza.ce.gov.br/inst/publ/ maisfortal ezainternas/educação.htm
13. Minayo MCS. 0 desafio do conhecimento: pesquisa qualitativa em saúde. São Paulo: Hucitec; Rio de Janeiro: Abrasco; 1994.

14. Lefévre F, Lefévre AMC. 0 discurso do sujeito coletivo: um novo enfoque em pesquisa qualitativa (desdobramentos). Caxias do Sul: EDUC; 2003.

15. Pacheco ALPB, Dupret L. Creche: desenvolvimento ou sobrevivência? Psicol. USP 2004; 15(3):103-116.

16. Barros AJD, Gonçalves EV, Borba CRS, Lorenzatto CS, M otta DB, Silva VRL, Schiroky VM. Perfil das creches de uma cidade de porte médio do sul do Brasil: operação, cuidados, estrutura física e segurança. Cad Saude Publica 1999;15(3):597-604.

17. Fonseca SS, Victora CG, Halpern R, Barros AJD, Lima RC, Monteiro LA, Barros F. Fatores de risco para injúrias acidentais em pré-escolares. J Pediatr 2002; 78(2):97-104.

18. Breysse P, Farr N, Galke W, Lanphear B, Morley R, Bergofsky $L$. The relationship between housing and health: children at risk. Environmental Health Perspectives 2004; 112(15):1583-1588.

19. Souza LJEX, Queiroz MVO, Barroso M GT. La estructura familiar de niños accidentados. Revista Cubana de Enfermería 1998; 14(3):209-218.

20. Souza LJEX, Barroso MGT. Acidente doméstico em crianças: abordagem conceitual. Acta Paulista de Enfermagem 1999; 12(1):70-76.

21. M artins CBG, Andrade SM. Epidemiologia dos acidentes e violência entre menores de 15 anos em município da Região Sul do Brasil. Rev Latino-am Enfermagem 2005; 13(4):530-537.

22. Gaspar VLV, Lamounier JA, Cunha FM, Gaspar JC. Fatores relacionados a hospitalizações por injúrias em crianças e adolescentes. J Pediatr 2004; 80(6):447-452.

23. Towner $E$, Ward $H$. Prevention of injuries to children and young people: the way ahead for the UK. Inj. Prev. 1998; 4(Suppl.1): S117-S125.

24. Vieira LJES, Silva AND, Frota MA, Albuquerque VLM. Envenenamento por carbamato em crianças: estudo descritivo. RBPS 2004; 17(4):193-199.

25. Blank D. Controle de injúrias sob a ótica da pediatria contextual. J Pediat 2005; 81(Supl.):S123-S136. 
26. M ello-da-Silva CA, Fruchtengarten L. Riscos químicos ambientais à saúde da criança. J Pediatr 2005; 81(Supl. 5):S155-S163.

27. Paes CEN, Gaspar VLV. As injúrias não intencionais no ambiente domiciliar: a casa segura. J Pediatr 2005; 81(Supl. 5):S146-S154.

28. Vieira LJES, Araújo KL, Catrib AMF, Vieira ACVC. 0 lúdico na prevenção de acidentes em crianças de 4 a 6 anos. RBPS 2005; 18(2):78-84.

29. Sperandio AM G, Correa CRS, Serrano MM, Rangel HA. Caminho da construção coletiva em ambientes saudáveis - São Paulo, Brasil. Cien Saude Colet 2004; 9(3):643-654.

30. Becker D, Edmundo K, Nunes NR, Bonatto D, Souza R. Empowerment e avaliação participativa em um programa de desenvolvimento local e promoção da saúde. Cien Saude Colet 2004; 9(3):655-667.
31. Conhen SC, Cynamon SE, Kligerman DC, Assumpção RF. Habitação saudável no Programa Saúde da Família (PSF): uma estratégia para as políticas públicas de saúde e ambiente. Cien Saude Colet 2004; 9(3):807-813

32. Harada MJCS, Pedroso GC, Ventura RN. A comunidade segura. J Pediatr 2005; 81(Supl. 5):S137-S145.

33. Liberal EF, Aires RT, Aires MT, Osório ACA. Escola segura. J Pediatr 2005; 81(Supl. 5):S155-S163.

34. Veríssimo M LOR, Fonseca RMGS. O cuidado da criança segundo trabalhadoras de creches. Rev Latino-am Enfermagem 2003; 11(1):28-35.

Artigo apresentado em 16/03/2006

Aprovado em 10/01/2007

Versão final apresentada em 29/02/2008

Apêndice 1. Instrumento de coleta de dados - Identificação dos participantes.

1) Dados pessoais

$\begin{array}{cccc}\text { Idade: } & \text { Sexo: F ( ) } & \text { M ( ) } & \\ \text { Escolaridade- } & \text { Superior: } & \text { Completo ( ) } & \text { Incompleto ( ) } \\ \text { Ensino médio } & & \text { Completo ( ) } & \text { Incompleto ( ) } \\ \text { Ensino fundamental } & & \text { Completo ( ) } & \text { Incompleto ( ) }\end{array}$

2) Dados profissionais

Realizou curso de profissionalização ou aperfeiçoamento voltado para a educação infantil? SIM ( ) NÃO ( ) Tempo de trabalho com educação infantil - creches?

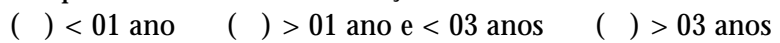

Faixa etária que trabalha atualmente:

( ) zero a 1 ano ( ) 1 a 2 anos ( ) 2 a 3 anos e meio

3) Entrevista semi-estruturada

1. Descreva o seu conhecimento sobre acidentes domésticos com crianças.

2. Na sua concepção, o que é possível ser feito para evitar a ocorrência de acidentes domésticos com crianças?

3. Você trabalha com a prevenção de acidentes domésticos aqui na creche?

4. Relate de que maneira a prevenção de acidentes domésticos é abordada na creche.

5. Descreva a participação das famílias nessa prevenção de acidentes.

6. No caso de alguma criança acidentar-se aqui na creche, como você procede?

7. Você recebeu orientação sobre prevenção de acidentes com crianças?

8. Como você acha que a prevenção de acidentes domésticos em crianças deveria ser abordada na creche?

9. Considerando seu conhecimento atual sobre acidentes domésticos, você acha que sabe trabalhar com a prevenção de acidentes domésticos com crianças aqui na creche?

10. Como você construiria ações de prevenção de acidentes para a "sua" creche? 